\title{
Critical Thinking and Its Relevant Factors among Undergraduates
}

\section{Yongmei Hou ${ }^{*}$}

Department of Psychology, School of Humanity and Administration, Guangdong Medical University, Dongguan, Guangdong, 523808, China

\section{ARTICLE INFO}

Article history

Received: 1 June 2021

Revised: 10 June 2021

Accepted: 15 October 2021

Published Online: 30 October 2021

\section{Keywords:}

Undergraduates

Critical thinking

Related factors

Multiple stepwise linear regression

\begin{abstract}
To explore the present status of Critical thinking and its relevant factors among undergraduates. A stratified random sampling was used to select 1013 undergraduates from 7 full-time colleges in Guangdong province. They were investigated with California Critical Thinking Disposition Inventory-Chinese Version (CTDI-CV) and a Self-Compiled Personal General Information Questionnaire. (1) The total score of CTDI-CV was (254.16 \pm 38.80$)$. The undergraduates in the four levels of critical thinking of comprehensive strong, relatively strong, contradictory scope and serious opposition accounted for $1.78 \%, 5.31 \%, 87.4 \%$ and $5.51 \%$ of this group, respectively. (2) Multiple stepwise linear regression showed that the total score of CTDI-CV was positively correlated with the following 10 factors such as grade, family economic status, part-time experience, the teaching method used most commonly, like reading logic books, like reading reviews or essays, father's warmth, mother's warmth, openness and responsibility ( $\beta=.142$ to .701 , all $P<.05$ ). The following 5 factors such as father's negation, father's overprotection, mother's negation, mother's overprotection and neuroticism were negatively correlated with the total score of CTDI-CV ( $\beta=-.381$ to -. 616 , all $P<0.05$ ). The overall level of critical thinking among undergraduates is relatively low. College Students' critical thinking may be related to many factors such as family rearing, school education and personal characteristics.
\end{abstract}

implicit attitude and tendency, which is also the basis of the former. Critical thinking helps people develop independent and logical thinking in the information society, effectively identify information and make decisions quickly and correctly, and then innovate and start businesses. Therefore, as an indispensable part of higher education, the cultivation of critical thinking of college students has been a hot topic in education in various countries ${ }^{[4-6]}$. However, in the traditional teaching mode, critical thinking has not been well developed and cultivated and leads to the low critical thinking ability of college students, which affects their academic

\footnotetext{
*Corresponding Author:

Yongmei Hou,

Department of Psychology, School of Humanity and Administration, Guangdong Medical University, Dongguan, Guangdong, 523808, China;
}

Email: 2184456621@qq.com 
achievement and work performance ${ }^{[7-9]}$.

As for the influencing factors of college students' critical thinking, previous studies involved the following four categories: (1) Biological factors, such as the executive function of the brain ${ }^{[10]}$. (2) Psychosocial factors. Demographic factors, for example, grade, age, gender, place of origin, major, college entrance scores, academic achievement, family economic status ${ }^{[11-16]}$, etc. Parenting style and parent-child relationship ${ }^{[17,18]}$. Teaching and educational factors. They are mainly power distance ${ }^{[19]}$, teaching methods ${ }^{[20-24]}$, learning methods ${ }^{[25,26]}$, social practice ${ }^{[27]}$, teaching equipment and means ${ }^{[28,29]}$. Personality characteristics such as learning motivation, self-confidence, self-esteem, optimism, emotional intelligence, metacognitive skills, problem solving skills and academic self-efficacy ${ }^{[30-33]}$.

To sum up, previous studies focused on psychosocial factors, and there are no unified opinions on the role of many factors yet. Moreover, most studies only focused on the role of one or two factors, and failed to reveal the role of various influencing factors and the relationship between different factors.

Based on the above analysis, this study intends to adopt a large sample and multi center questionnaire survey to explore the current situation and influencing factors of college students' critical thinking in Guangdong.

\section{Objects and Methods}

\subsection{Objects}

From March to May, 2020, a total of 1200 questionnaires were distributed to undergraduates from freshmen to seniors from Guangdong Medical University, Dongguan Institute of technology, Guangzhou Institute of physical education, Xinghai Conservatory of music, Guangdong University of Finance and economics, Guangdong Ocean University and Shenzhen University by a stratified random sampling. 1013 valid questionnaires were returned, with an effective rate of $84.4 \%$. There are 481 boys and 532 girls; 994 Han and 19 minority; 264 freshmen, 250 sophomores, 245 juniors and 254 seniors; 192 in comprehensive universities, 241 in science and engineering universities, 91 in finance and economics universities, 99 in agriculture universities, 252 in medicine universities, 40 in sports universities and 98 art universities; 814 only children and 199 non only children; 11 rich families, 533 well-off families, 427 food and clothing families and 42 poor families; 629 long-term residents in cities and towns and 384 longterm residents in rural areas; 44 excellent students, 517 good students, 399 average students, 49 passing students and 4 failing students.

\subsection{Tools}

\subsubsection{Critical Thinking Disposition Inventory- Chinese Version (CTDI-CV)}

It was revised by Peng Meici et al. ${ }^{[34]}$ according to California Critical Thinking Dispositions Inventory (CCTDI). CTDI-CV has 70 items, which are divided into seven subscales: seeking truth, open mind, analytical ability, systematic ability, self-confidence of critical thinking, thirst for knowledge and cognitive maturity. The 6-point scoring method is used to score from 1 to 6 points corresponding to "very disagree" to "very agree". The higher the total score, the stronger the tendency of critical thinking. The total score is 70 to 420 . The evaluation rules are as follows:

If the total score is 350 to 420 , indicating that the subject's critical thinking tendency is comprehensively strong; If the total score is 280 to 349 , indicating that the subject's critical thinking tendency is relatively strong; If the total score is 210 to 279 , indicating that the subject's critical thinking tendency is in the range of contradiction; If the total score is 70 to 209 , indicating that the subject's critical thinking tendency is seriously opposed to critical thinking. The scores of each subscale ranged from 10 to 60. The evaluation rules of each subscale are as follows: If the score is higher than 50 , indicating that the tendency is very strong; A score of 40 to 49 indicates that the tendency is relatively strong, and a score of 30 to 39 indicates that the tendency is in a state of contradiction; A score of 10 to 29 indicates that the tendency deviates from the requirement of critical thinking. In this study, the Cronbach' a coefficient of the total scale is 0.84 , and the Cronbach' a coefficient of each subscale is 0.68 to 0.77 .

\subsubsection{Short-Form Egna Minnen av Barndoms Uppfostran (s-EMBU)}

It's a self-reported questionnaire, compiled by Marcus (2003) and revised into Chinese version by Jiang prize (2010) ${ }^{[35]}$. s-EMBU is divided into father's subscale and mother'ssubscale, each with 21 items and the same content, including three dimensions: negation, emotional warmth and overprotection. The 4-point scoring method is used to score from 1 to 4 points corresponding to "never" to "always". The average score of each dimension represents the subjects' perceived parenting style. The higher the dimension score, the stronger its tendency. In this study, the cronbach' $\alpha$ coefficient of the total scale is 0.85 . The Cronbach' $\alpha$ coefficients of the father subscale and the mother subscale were 0.87 and 0.82 , respectively. The Cronbach' $\alpha$ coefficient of each dimension is 0.69 to 0.78 .

DOI: http://dx.doi.org/10.26549/jetm.v5i2.7000 


\subsubsection{NEO Five-Factor Inventory (NEO-FFI)}

It's a self-report scale, developed on the basis of NEOPI which compiled by McCrae and Casta (1985), and revised into Chinese version by Yao Ruosong (2010) ${ }^{[36]}$. NEO-FFI has 60 questions, Divided into five dimensions, namely neuroticism (n), extraversion (E), openness (o), agreeableness (a) and responsibility (c). The 5-point scoring method is used to score from 1 to 5 points corresponding to "very disagree" to "very agree". In this study, The Cronbach's $\alpha$ coefficient of each dimension is 0.73-0.81.

\subsubsection{Self-Compiled Personal General Information Questionnaire}

The CNKI, Wanfang database, VIP database, Baidu, google, Pubmed and other search engines were used to search the literature about college students' critical thinking (706 in Chinese and 56749 in foreign languages). Based on that, the basic content of the questionnaire was constructed, with a total of 23 items. Combined with the results of 3 collective discussions with 10 representatives of undergraduates and 5 experts in the field of higher education, 3 items were deleted and 1 item was added. The final questionnaire for personal general information involves 21 items, which includes age, gender, grade, school category, major category, academic achievement, family economic status, place of origin, only child or not, part-time experience, father's education, mother's education, reading habits, teaching methods, learning methods, teaching assistant section, etc.

\subsection{Data Manipulation}

SPSS 20.0 was used for statistical analysis. Descriptive statistics were used to calculate the average score and standard deviation of each scale; Pearson product correlation was used to explore the correlation between variables; multiple stepwise linear regression was used to analyze the related factors of CTDI-CV total score.

\section{Results}

\subsection{Descriptive Statistics of Each Scale Scores}

There were 18 (1.78\%), 54 (5.31\%), 885 (87.4\%) and $56(5.5 \%)$ college students whose critical thinking was in the level of comprehensively strong, relatively strong, contradictory range and serious opposition, respectively.

It can be seen from table 1 that the overall level of critical thinking of college students in this group (average score of CTDI-CV $=217.84 \pm 49$ ) is in the scope of contradiction.

Table 1. Descriptive statistics of total score and dimension (subscale) scores of each scale $(\mathrm{n}=1013)$

\begin{tabular}{|c|c|c|c|c|c|c|c|}
\hline Dimension & Min & Max & M & $\mathrm{SD}$ & Number of items & $\begin{array}{c}\text { Average score of } \\
\text { items }\end{array}$ & $\begin{array}{c}\text { Standard deviation of each } \\
\text { item }\end{array}$ \\
\hline seeking truth & 23 & 54 & 41.57 & 5.94 & 10 & 4.16 & 0.59 \\
\hline Open mind & 21 & 52 & 39.28 & 6.23 & 10 & 3.93 & 0.62 \\
\hline Analysis ability & 19 & 53 & 35.85 & 4.57 & 10 & 3.59 & 0.46 \\
\hline Systematic ability & 12 & 45 & 34.20 & 6.60 & 10 & 3.42 & 0.66 \\
\hline Self-confidence of critical thinking & 16 & 50 & 33.56 & 3.74 & 10 & 3.36 & 0.37 \\
\hline Thirst for knowledge & 18 & 32 & 34.61 & 7.29 & 10 & 3.46 & 0.73 \\
\hline Cognitive maturity & 15 & 39 & 35.09 & 4.43 & 10 & 3.51 & 0.44 \\
\hline Total score of CTDI-CV & 169 & 338 & 254.16 & 38.80 & 70 & 3.63 & 0.55 \\
\hline Father's negation & 6 & 17 & 13.55 & 2.56 & 6 & 2.26 & 0.45 \\
\hline Father's overprotection & 8 & 21 & 12.72 & 1.78 & 8 & 1.61 & 0.25 \\
\hline Mather's negation & 7 & 17 & 11.93 & 1.64 & 6 & 1.99 & 0.27 \\
\hline Mather's warmth & 18 & 35 & 23.18 & 5.04 & 7 & 3.32 & 0.72 \\
\hline Mather's overprotection & 9 & 28 & 19.02 & 4.49 & 8 & 2.38 & 0.58 \\
\hline Openness & 27 & 57 & 42.16 & 6.25 & 12 & 3.51 & 0.52 \\
\hline Responsibility & 25 & 50 & 37.04 & 4.69 & 12 & 3.09 & 0.39 \\
\hline Extraversion & 22 & 45 & 38.25 & 6.43 & 12 & 3.19 & 0.54 \\
\hline Agreeableness & 28 & 52 & 39.12 & 3.92 & 12 & 3.26 & 0.33 \\
\hline Neuroticism & 19 & 47 & 33.87 & 5.57 & 12 & 2.82 & 0.47 \\
\hline
\end{tabular}




\subsection{Correlation analysis of s-EMBU, NEO-FFI and CTDI-CV}

It can be seen from Table 2 that the total score of CTDI$\mathrm{CV}$ was significantly correlated with the six dimensions of s-EMBU and the scores of openness, responsibility and neuroticism in NEO-FFI (all $P<0.01$ ).

\subsection{Multiple Stepwise Linear Regression Analysis on the Related Factors of College Students' Critical Thinking}

\subsubsection{Variable Assignment}

First, the possible situations (alternative answers) of the demographic classification variables that may affect the total score of CTDI-CV are assigned, and the results are shown in Table 3.

\subsubsection{Multiple Stepwise Linear Regression Analysis of Related Factors of College Students' Critical Thinking}

Taking the total score of CTDI-CV as the dependent variable and the factors that may be related to the total score of CTDI-CV (including demographic variables, six dimension scores of s-EMBU and five dimension scores of NEO-FFI) as the independent variables, a multiple stepwise linear regression is carried out within the $95 \%$ confidence interval, the results are shown in Table 4.

It can be seen from table 4 that 10 factors such as grade, family economic status, part-time experience, the teaching methods used most commonly, like reading logic books, like reading reviews or essays, father's warmth, mother's warmth, openness and responsibility are positively correlated with the total score of CTDI-CV ( $\beta=.142$ to .701 , all $P<0.05$ ). Five factors such as father's negation,

Table 2. Correlation analysis of s-EMBU, NEO-FFI and CTDI-CV scores $(\mathrm{n}=1013)$

\begin{tabular}{|c|c|c|c|c|c|c|c|c|}
\hline Dimension & Seeking truth & Open mind & $\begin{array}{l}\text { Analysis } \\
\text { ability }\end{array}$ & $\begin{array}{l}\text { Systematic } \\
\text { ability }\end{array}$ & $\begin{array}{l}\text { Confidence of } \\
\text { critical thinking }\end{array}$ & $\begin{array}{l}\text { Thirst for } \\
\text { knowledge }\end{array}$ & $\begin{array}{c}\text { Cognitive } \\
\text { maturity }\end{array}$ & $\begin{array}{c}\text { Total score of } \\
\text { CTDI-CV }\end{array}$ \\
\hline Father's negation & $-.226^{* *}$ & $-.253^{* *}$ & -.011 & -.022 & $-.124^{* *}$ & $-.131^{* *}$ & $-.233^{* *}$ & $-.278^{* *}$ \\
\hline Father's warmth & $.374^{* * *}$ & $.276^{* *}$ & .023 & .035 & $.436^{* *}$ & $.213^{* * *}$ & $.198^{* *}$ & $.328^{* *}$ \\
\hline Father's overprotection & $-.310^{* *}$ & $-.198^{* *}$ & -.014 & -.030 & $-.173^{* *}$ & $-.244^{* *}$ & $-.169^{* *}$ & $-.261^{* *}$ \\
\hline Mather's negation & $-.246^{* *}$ & $-.220^{* *}$ & -.007 & -.019 & $-.107^{* *}$ & $-.188^{* *}$ & $-.208^{* * *}$ & $-.252^{* * *}$ \\
\hline Mather's overprotection & $-.283^{* *}$ & $-.164^{* * *}$ & -.009 & -.041 & $-.162^{* *}$ & $-.157^{* * *}$ & $-.205^{* *}$ & $-.218^{* *}$ \\
\hline Openness & $.347^{* *}$ & $.811^{* *}$ & $.148^{* * *}$ & .059 & $.268^{* *}$ & $.183^{* *}$ & $.148^{* *}$ & $.530^{* *}$ \\
\hline Responsibility & $.392^{* *}$ & .033 & .019 & .044 & $.324^{* * *}$ & $.338^{* *}$ & $.309^{* * *}$ & $.351^{* *}$ \\
\hline Extraversion & .044 & .053 & .026 & .036 & .028 & .032 & .035 & .037 \\
\hline Agreeableness & -.039 & -.018 & .034 & -.037 & -.049 & .041 & $.122^{* *}$ & -.027 \\
\hline
\end{tabular}

Notes: $* P<0.05, * * P<0.01$ 
Table 3. Variable assignment

Items Options and assignment

Grade $0=$ freshman, $1=$ sophomore, $2=$ junior, $3=$ senior

Gender $0=$ Male, $1=$ Female

3. Major categories: $0=$ Engineering, $1=$ science, $2=$ economics and trade, $3=$ management, $4=$ linguistics, $5=$ medicine and pharmacy, $6=$ art and design

4. School categories $0=$ science and engineering, $1=$ liberal arts, $2=$ agriculture $3=$ medicine, $4=$ sports, $5=$ art, $6=$ comprehensive

5. Only child or not $0=\mathrm{No}, 1=\mathrm{Yes}$

6. Family economic status $0=$ poverty, $1=$ food and clothing, $2=$ well-off, $3=$ rich

7. Origin $0=$ city or town, $1=$ country

8. Do you have part-time experience? $0=$ none, $1=$ yes

9. Academic achievement 0 =unqualified, $1=$ qualified, $2=$ medium, $3=$ good, $4=$ excellent

10. Father's education $0=$ primary school and below, $1=$ junior high school, $2=$ senior high school or technical secondary school, $3=$ junior college, 4 = Bachelor's degree, 5 = Master's degree, 6 = doctor's degree

11. Mather's education $0=$ primary school and below, $1=$ junior high school, $2=$ senior high school or technical secondary school, $3=$ junior college, 4 = Bachelor's degree, $5=$ Master's degree, $6=$ doctor's degree

12. Do you like reading philosophy monographs? $0=$ not at all, $1=$ not very much, $2=$ it doesn't matter, $3=$ a little, $4=$ very much

13. Do you like reading logic monographs $0=$ not at all, $1=$ not very much, $2=$ it doesn't matter, $3=$ a little, $4=$ very much

14. Do you like reading math books $0=$ not at all, $1=$ not very much, $2=$ it doesn't matter, $3=$ a little, $4=$ very much

15. Do you like reading scientific papers $0=$ not at all, $1=$ not very much, $2=$ it doesn't matter, $3=$ a little, $4=$ very much

16. Do you like reading reviews or essays $0=$ not at all, $1=$ not very much, $2=$ it doesn't matter, $3=$ a little, $4=$ very much

17. Do you like reading prose $0=$ not at all, $1=$ not very much, $2=$ it doesn't matter, $3=$ a little, $4=$ very much

18. Do you like reading novels $0=$ not at all, $1=$ not very much, $2=$ it doesn't matter, $3=$ a little, $4=$ very much

19. Which teaching method do you adopt most often? $0=$ traditional teaching method, $1=$ role play, $2=$ PBL teaching method, $3=$ evidence-based practice teaching, $4=$ simulation debate

20. What kind of learning style do you use most often? $0=$ individual learning, $2=$ cooperative learning

21. Which teaching aids do you used most commonly $0=$ traditional teaching means, $1=$ conventional multimedia, $2=$ network teaching platform

Table 4. Multiple stepwise linear regression analysis of main influencing factors of CTDI-CV total score

\begin{tabular}{|c|c|c|}
\hline \multicolumn{2}{|c|}{ Dependent variable Independent variable } & \multirow{2}{*}{$\beta$ tP $R^{2} R_{a d j}^{2}$} \\
\hline \multicolumn{2}{|r|}{ B Standard error } & \\
\hline & Total score Grade .271 .047 & $.1577 .414<.001 .539 .534$ \\
\hline of CTDI-CV & Family economic status .257 .071 & .1942 .640 .008 \\
\hline & part-time experience .278 .063 & .2012 .903 .006 \\
\hline & teaching method .838 .106 & $.7014 .566<.001$ \\
\hline & Like logic monographs .797 .086 & $.6894 .734<.001$ \\
\hline & Like reviews or essays .589 .093 & $.4128 .471<.001$ \\
\hline & Father's negation -.691 .089 & $-.616-2.029 .040$ \\
\hline & Father's warmth .503 .139 & .4572 .785 .005 \\
\hline & Father's overprotection -.352 .048 & $-.298-4.279<.001$ \\
\hline & Mather's negation -.477 .062 & $-.399-5.488<.001$ \\
\hline & Mather's warmth .418 .054 & $.3567 .343<.001$ \\
\hline & Mather's overprotection -.501 .137 & $-.381-8.611<.001$ \\
\hline & Openness .664 .097 & $.6034 .492<.001$ \\
\hline & Responsibility .387 .094 & .2862 .468 .014 \\
\hline & Neuroticism -.528 .083 & $-.468-2.091 .036$ \\
\hline
\end{tabular}


father's overprotection, mother's negation, mother's overprotection and neuroticism are negatively correlated with the total score of CTDI-CV ( $\beta=-.381$ to -. 616 , all $P$ $<0.05$ ).

\section{Discussion}

The total score of CTDI-CV and the scores of each subscale in this group are in the contradictory range, with $87.4 \%$ of the students in the contradictory range, and $5.9 \%$ of them in serious opposition, which is consistent with the results of previous studies ${ }^{[7-9],}$ suggesting that the level of critical thinking is not high, which is common among college students.

Multiple stepwise linear regression shows that 10 factors such as grade, family economic status, part-time experience, the teaching method used most commonly, like reading logic books, like reading reviews or essays, father's warmth, mother's warmth, openness and responsibility are positively correlated with the total score of CTDI-CV. Five factors such as father's negation, father's overprotection, mother's negation, mother's overprotection and neuroticism are negatively correlated with the total score of CTDI-CV.

Grade positively predicts the total score of CTDI$\mathrm{CV}$, which is consistent with the results of the research of nippod ${ }^{[37]}$, but age can't enter the regression equation, suggesting that natural physiological maturity is not the main influencing factor of critical thinking, and relatively speaking, mental maturity (including the expansion of knowledge and the improvement of understanding ability) can promote the development of critical thinking.

Family economic status and part-time experience are independent positive predictors of CTDI-CV total score, which is consistent with the results of previous research ${ }^{[15]}$, suggesting that the superficial capital partition between classes has changed into the deep ability partition. Family economic status reflects the adequacy of family members' living conditions and the richness of learning and practical activities. Good family economic status can provide sufficient living conditions for family members, so that they have opportunities to participate in more diverse learning and practical activities, so as to expand their knowledge and improve their ability of analysis and criticism. Part time job is the most practical activity close to social life, which makes individuals contact with diversified social phenomena and promotes the development of individual's ability of comparison, identification and criticism.

Three factors such as the teaching method used most commonly, like to read logic books, like to read reviews or essays positively predict the total score of CTDI-CV, which is consistent with the results of previous studies ${ }^{[20-}$ ${ }^{26]}$, suggesting that learning materials and methods which are rich in organization and can inspire thinking can improve critical thinking.

Father's warmth and mother's warmth positively predict the total score of CTDI-CV, while father's negation, father's overprotection, mother's negation and mother's overprotection negatively predict the total score of CTDI-

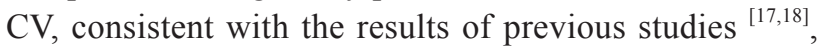
suggesting that moderate emotional connection and democratic and respectful family atmosphere are helpful for the children to be good at thinking, exploring and questioning.

Openness and responsibility positively predict the total score of CTDI-CV, while neuroticism negatively predicts the total score of CTDI-CV, which is consistent with the results of previous studies ${ }^{[33]}$ suggesting that people with curiosity and imagination, wide interests, sensitive to things, stable emotions and strong self-control ability are more able to think patiently, analyze deeply, find problems and trigger critical thinking.

\section{References}

[1] FACIONE PA. Critical Thinking: A statement of expert consensus for purposes of educational assessment and instruction[C]. Newark: American Philosophical Association, 1990.

[2] Ennis R. A logical basis for measuring critical thinking skills[J]. Educational Leadership, 1985, 43(2): 44-48.

[3] Dong Yu. On the role of critical thinking education in innovation mechanism reform[J]. Industry and Information Education, 2016, (6): 18-26.

[4] Hassan KE, Madhum G. Validating the watson glaser critical thinking appraisal[J]. Higher Education, 2007, 54(3): 361-383.

[5] Peng Zhengmei, Deng Li. Towards the core of education reform: cultivating critical thinking skills as the core of skills in the 21 st century[J]. Education Development Research, 2017, 37 (24): 57-63

[6] Chu Hongqi. International vision of core literacy and China's position: the improvement of China's national quality and the transformation of education goals in the 21st century[J]. Education Research, 2016,37 (11): 8-18

[7] Zhang Mei, Ru Jingfei, Yin Yong. Research on the current situation and causes of college students' critical thinking[J]. Journal of Chongqing University (SOCIAL SCIENCE EDITION), 2016, (3): 113-121.

[8] Chen Xiaofang, Ma Jinxiang, Liao Jianfeng. Current situation and influencing factors of critical thinking 
ability of medical students in a university in Guangzhou[J]. Occupation and Health. 2015, 31(10): 13751378

[9] Ye Yinghua, Yin Yanmei. Cognitive characteristics and cultivation strategies of college students' critical thinking: An empirical study based on group cooperation[J]. Educational Development Research, 2019, (11): 66-74.

[10] Li Shuangshuang, Ren Xuezhu, Schweizer Karl, et al. Executive functions as predictors of critical thinking: Behavioral and neural evidence[J]. Learning and Instruction, 2021, 71: 101376.

[11] Katrina Roohr, Margarita Olivera-Aguilar, Guangming Ling, et al. A multi-level modeling approach to investigating students' critical thinking at higher education institutions $[\mathrm{J}]$. Assessment \& Evaluation in Higher Education, 2019, 44(6): 946-960.

[12] James Goodpasture, Mark Speece, Jeremy Cripps. An Analysis of Critical Thinking Skills amongst Business Students in Kuwait[J]. Economics and Culture, 2020, 17(1): 5-16.

[13] Yang Zhendong, Gu Guofeng, Liu Tao. Comparison of critical thinking tendency of liberal arts and science students -- Based on the investigation of a university in Guilin[J]. Journal of Guilin Teachers College, 2020, 34 (6): 100-106

[14] Zou fengqiong. Investigation on critical thinking tendency of college students[J]. Journal of Jilin Radio and TV University. 2020, (11): 34-36.

[15] Wu Yongyuan, Shen Hong. Does family capital structure affect undergraduates' critical thinking ability? An empirical analysis based on the national undergraduate ability evaluation[J]. Chongqing Higher Education Research, (final draft) network launch time: 2020-10-23 14:54:33.

[16] Armend Tahirsylaj, Ninni Wahlström. Role of transnational and national education policies in realisation of critical thinking: The cases of Sweden and Kosovo[J]. The Curriculum Journal, 2019, 30(4): 484-503.

[17] Cho Hae Ryun, Yim So Youn. Convergence study between helicopter parenting, critical thinking disposition, and learning competence of nursing students $[\mathrm{J}]$. Journal of the Korea Convergence Society, 2018, 9(1): 501-507.

[18] Yangyang Wang, Tomoyasu Nakamura, Wakako Sanefuji. The influence of parental rearing styles on university students' critical thinking dispositions: The mediating role of self-esteem[J]. Thinking Skills and Creativity, 2020, 37: 37-46.

[19] Kim Hannah. The effect of power distance in school on instructor-student interaction, help seeking, critical thinking, and convergence thinking[J]. Journal of Convergence for Information Technology, 2020, 10 (4): 89-97.

[20] Abiogu Godwin C, Ede Moses Onyemaechi, Agah John J, et al. Cognitive-behavioural reflective training for improving critical thinking disposition of nursing students[J]. Medicine, 2020, 99(46): e22429-e22429.

[21] Soleiman Ahmady, Sara Shahbazi. Impact of social problem-solving training on critical thinking and decision making of nursing students[J]. BMC Nursing, 2020, 19(1): 24-211.

[22] Dimitris Pnevmatikos, Panagiota Christodoulou, Triantafyllia Georgiadou. Promoting critical thinking in higher education through the values and knowledge education (V a KE) method[J]. Studies in Higher Education, 2019, 44(5): 892-901.

[23] Mei $\square$ Rong Alice Chen, Gwo $\square$ Jen Hwang. Effects of a concept mapping $\square$ based flipped learning on EFL students' English speaking performance, critical thinking approach awareness and speaking anxiety[J]. British Journal of Educational Technology, 2020, 51(3): 817-834.

[24] Esra Kabataş Memiş, Büşra Nur Çakan Akkaş. Developing critical thinking skills in the thinking-discussion-writing cycle: The argumentation-based inquiry approach $[\mathrm{J}]$. Asia Pacific Education Review, 2020, 21(3): 441-453.

[25] Jun Zhang, Bowen Chen. The effect of cooperative learning on critical thinking of nursing students in clinical practicum: A quasi-experimental study[J]. Journal of Professional Nursing, 2020.

[26] Seung Gyu Lee. A study of critical thinking education through reading $[\mathrm{J}]$. The Korean Journal of Literacy Research, 2020, 11(1): 191-216.

[27] Esther H. Kuntjara. Students' reflection on their service-learning experience as a way of fostering critical thinking and as a peace building initiative[J]. Citizenship Teaching \& Learning, 2019, 14(2): 225-237.

[28] Misrulloh A, Dewi N R. Influence of science digital storytelling against motivation of learning and critical thinking ability learners[J]. Journal of Statistical Mechanics: Theory and Experiment, 2020, 1567(4): 042048.

[29] Yakob M, Saiman Sofiyan, Sari RP, et al. The effectiveness of science experiment through multimedia teaching materials to improve students' critical thinking[J]. Journal of Statistical Mechanics: Theory and Experiment.2020, 1567(4): 042018.

[30] Jung Hwa Yoon, Song Hyo Suk, Noh Ji Young, et al. Effects of a simulation-based Korean Advanced Life 
Support (KALS) program on knowledge, confidence, and critical thinking disposition for paramedic students[J]. The Korean Journal of Emergency Medical Services, 2020, 24(1): 57-66.

[31] Bo Ram Choi, JungIm Kim. Relationship between critical thinking disposition, self-efficacy, self-esteem and optimism of nursing students[J]. Indian Journal of Public Health Research \& Development, 2019, 10(11): 4615-4621.

[32] Sahanowas Sk, Santoshi Halder. Critical thinking disposition of undergraduate students in relation to emotional intelligence: Gender as a moderator $[\mathrm{J}]$. Heliyon, 2020, 6(11): e0547.

[33] ishak KOZIKOĞLU. Investigating critical thinking in prospective teachers: metacognitive skills, problem solving skills and academic self-efficacy[J]. Journal of Social Studies Education Research, 2019,
10(2): 111-130.

[34] Peng MEICI, Wang Guocheng, Chen Jile, et al. Reliability and validity of critical thinking ability scale[J]. Chinese Journal of nursing. 2004, 39 (9): 644-647

[35] Jiang Zhen, Lu Zhengrong, Jiang Pengjing, et al. Preliminary revision of the Chinese version of the simplified parenting style questionnaire[J]. Psychological Development and Education, 2010, (1): 94-99

[36] Yao Ruosong, Liang Leyao (2010). The application of NEO-FFI in college students[J]. Chinese Journal of clinical psychology, (4): 457-459

[37] Nippold Marilyn A, LaFavre Scott, Shinham Kristin. How adolescents interpret the moral messages of fables: Examining the development of critical thinking[J]. Journal of Speech, Language, and Hearing Research: JSLHR, 2020, 63(4): 1212-1226. 